\title{
Research on the Nonlinear Effect of Investment on Regional Economic Growth Based on Semi-Parametric Model
}

\author{
Xue Yong-gang \\ Medical Business School of GuangDong Pharmaceutical University \\ "Corresponding author. Email: xzyonggang@163.com
}

\begin{abstract}
Based on the data of regional economic growth in Guangdong Province from 2000 to 2019, this paper analyzes the impact of investment, consumption, human resources and export on regional economic growth based on semiparametric model. The conclusions can be gain as following: (1) Consumption and human resources have a greater role in promoting regional economic growth; (2) Investment has a nonlinear effect on regional economic growth. When the level of investment exceeds the threshold, it will no longer promote regional economic growth; (3) In the study of regional economic growth, the semi-parametric model has better fitting effect than the linear model, and is more suitable for the study of regional economic growth. The main suggestions are as follows: (1) We should increase the level of domestic demand and appropriately control the scale of investment. (2) Strengthen the training of human resources, improve the role of promoting regional economic growth
\end{abstract}

Keywords: Nonlinear influence, Regional economic growth, Semi-parametric model

\section{INTRODUCTION}

The 18th National Congress of the Communist Party of China proposed the innovation driven development strategy and the goal of transforming the economy from high-speed growth to high-quality development stage. Investment is an important factor in stimulating economic growth. Under the background of the change in the driving force of economic growth, does the role of investment in fixed assets still exist?

The relationship between investment and economic growth has always been one of the important issues discussed by domestic and foreign academic circles. Scholars have made relevant researches on the relationship between investment and economic growth from different angles. In terms of research methods, it mainly focuses on the research of time series, and mostly uses cointegration test, error correction model analysis, Granger causality test to conduct empirical research on the relationship between investment and economic growth. Some literatures also analyze the relationship between fixed asset investment and economic growth based on panel data model.
Because of the diminishing marginal output effect of production factors, it can not objectively grasp the impact of investment only to consider the linear relationship between investment and economic growth. Therefore, this paper intends to use the semi-parametric model to analyze the nonlinear impact of investment on economic growth, and compares the fitting effect with the linear model.

\section{LITERATURE REVIEW}

Economic growth is an important issue concerned by scholars all over the world. Onifade S T(2020) found that there is a long-term correlation between public expenditure and economic growth, government expenditure has a negative impact on economic growth, and public expenditure and domestic investment are the Granger causes of economic growth[1]; Hasan M $\mathrm{A}(2019)$ found that economic globalization and political globalization accelerate economic growth in the long run, but the impact of shortage is not obvious[2]; Haini $\mathrm{H}(2020)$ the empirical results show that financial institutions have a significant positive impact on economic growth, but the impact of financial market is not obvious[3]; Kalaitzi A(2020) found that export will increase investment in sectors with comparative 
advantages, thus increasing economic growth rate. At the same time, export will increase foreign exchange inflow, which will also stimulate economic growth[4]; Gani A(2020) found that China's economic growth has a significant positive impact on Africa, while India's economic impact is not significant[5]; Qamruzzaman, M.(2018) found that financial innovation and economic growth have long-term cointegration. In the long run, financial innovation has a positive impact on economic growth, but the short-term impact is not obvious[6]; Olayungbo D O(2019) found that both long-term and short-term financial development has a positive impact on economic growth[7]; Nguyen H T(2020) found that greenfield investment and cross-border M\&A have different effects on economic growth, which is important to the policy of attracting foreign investment[8]; Mohamed Abdouli(2017) found that the inflow of foreign capital can accelerate the economic growth of MENA countries, and the economic growth is easy to cause environmental degradation[9]. Ge L(2020) The model of economic growth in Guangdong-Hong Kong-Macao Greater Bay Area is established by big data mining method. The clustering algorithm of economic growth trend prediction model is established by fuzzy fusion clustering method. The simulation model shows that the model has better prediction ability and accuracy [10]. Bsenberg S(2018) In order to study the impact of capital tax on macroeconomic output, it makes an empirical analysis based on the data samples of 79 countries from 1996 to 2011 and exogenous growth model, it is found that reducing capital tax has a positive impact on output[11]. Mushtaq(2016) Based on the time series data of Pakistan from 1961 to 2013, it is found that there is no Granger causality between the banking savings \& lending business and the economic growth in the long term and short term through cointegration test and Granger causality test, but the economic growth affects the bank's lending business, so the lending procedures should be simplified during the peak period of economic growth. [12]. Chen S W(2018) studies the causality between energy consumption and economic growth of 29 provinces in China. Based on the panel Granger causality test, we find that there is no causality between the results of two provinces, the results of 16 provinces have two-way causality, and the results of 11 provinces have no direct causality [13].

\section{DATA AND METHOD}

Based on the sample of economic growth in Guangdong Province from 2000 to 2019, this paper analyzes the impact of investment, human resources, consumption and export on regional economic growth. Fixed asset investment is used as investment index, employment population as human resources, total retail sales of consumer goods as consumption demand, and import and export as external economic impact.
The semi-parametric model assumes that the relationship between independent variables and dependent variables is partly linear, and the other part is nonlinear. It assumes that there are $\mathrm{p}+\mathrm{q}$ variables, There is a linear relationship between $x_{1}, x_{2}, x_{3} \ldots x_{p}$ and dependent variables $y$. There is a nonlinear relationship between $z_{1}, z_{2}, z_{3} \ldots z_{q}$ and dependent variables $\mathrm{y}$, which has a linear relationship with the dependent variable after nonlinear transformation by kernel function $\Phi(z)$. The basic form of the semiparametric model is as Equation (1).

$y=X \beta+\Phi(z) \omega+\varepsilon$

Where $\varepsilon$ is the random error term. The coefficients $\beta$ and $\omega$ are estimated using the sample data as Equation (2).

$\hat{y}=X \hat{\beta}+\Phi(z) \hat{\omega}$

After the initial value of $\hat{\beta}^{(0)}$ is given, the residual $\varepsilon^{(0)}=y-X \hat{\beta}^{(0)}$ is obtained, and then the kernel regression is performed on some nonlinear independent variables with $\varepsilon^{(0)}$ as the dependent variable. The fitting value $K\left(K^{2}\right)+K \bullet \varepsilon^{(0)}$ is obtained, the dependent variable $\hat{y}=y-K\left(K^{2}\right)+K \bullet \varepsilon^{(0)}$ is updated, and the updated dependent variable y is used to calculate $\hat{\beta}^{(1)}=\left(X^{\mathrm{T}} \mathrm{X}\right)^{-1} \mathrm{X}^{T} \hat{y}$. $\mathrm{K}$ is the Gram matrix corresponding to the kernel function. The iteration is repeated until $\left|\hat{\beta}^{(k+1)}-\hat{\beta}^{k}\right|$ is less than the given precision[14].

In order to compare the fitting effect of linear model and semi parametric model, this paper calculates MAE (Mean Absolute Error), MSE(Mean Square Error) and MAPE(Mean Absolute Percentage Error), and the calculation methods are as Equation (3), Equation (4) and Equation (5).

$$
\begin{aligned}
& M S E=\frac{1}{n} \sum_{i=1}^{n}\left(\hat{y}_{i}-y_{i}\right)^{2} \\
& M A E=\frac{1}{n} \sum_{i=1}^{n}\left|\hat{y}_{i}-y_{i}\right| \\
& M A P E=\frac{100 \%}{n} \sum_{i=1}^{n}\left|\frac{\hat{y}_{i}-y_{i}}{y_{i}}\right|
\end{aligned}
$$

\section{EMPIRICAL RESULTS}

The empirical results of linear model (Model 1) and semi-parametric model (Model 2) are shown in Table 1. It can be seen from Table 1 that all coefficient estimates 
pass the significance test at the significance level of $10 \%$ or above.

Table 1 The results of empirical model

\begin{tabular}{lcccc}
\hline \multirow{2}{*}{ variable } & \multicolumn{2}{c}{ Model 1 } & \multicolumn{2}{c}{ Model 2 } \\
& coef & P-value & coef & P-value \\
\hline Investment & 0.027 & 0.10 & ----- & ---- \\
\hline Labor & 0.985 & 0.03 & 0.921 & 0.10 \\
\hline Consume & 0.641 & 0.00 & 0.991 & 0.00 \\
\hline Export & 0.068 & 0.06 & 0.048 & 0.08 \\
\hline MAE & 0.0206 & & 0.0087 & \\
\hline MSE & & & & \\
\hline MAPE(\%) & 0.0006 & & 0.0001 & \\
\hline
\end{tabular}

Firstly, the results of linear model show that investment, human resources, consumption and export have positive effects on economic growth, among which human resources have the greatest impact on economic growth, with the estimated coefficient of 0.985 ; consumption has a significant impact on economic growth, with the estimated coefficient of 0.641 ;investment and export have a small impact on economic growth, with the estimated coefficient of 0.027 and 0.068 , respectively.

Second, considering the nonlinear factors of investment, the impact of consumption on economic growth is significantly increased, with the estimated coefficient of 0.991 ; the impact of manpower on economic growth is slightly weakened, with the estimated coefficient of 0.921 ; the impact of export on economic growth is slightly weakened, with the estimated coefficient of 0.048 .

Third, comparing the two models, the semiparametric model is more accurate than the linear model. The MAE (mean absolute errors) of the two models were 0.0206 and 0.0087 , MSE (mean square error) were 0.0006 and 0.0001, and MAPE (mean absolute percentage error) were 0.1953 and 0.0815 .

Figure 1 is the nonlinear influence curve of investment on regional economic growth. It can be seen from the figure that economic growth will be promoted with the increase of investment, and the curve will show a downward trend when the investment increases to a certain level.

\section{CONCLUSION}

The following conclusions can be drawn from the empirical results:

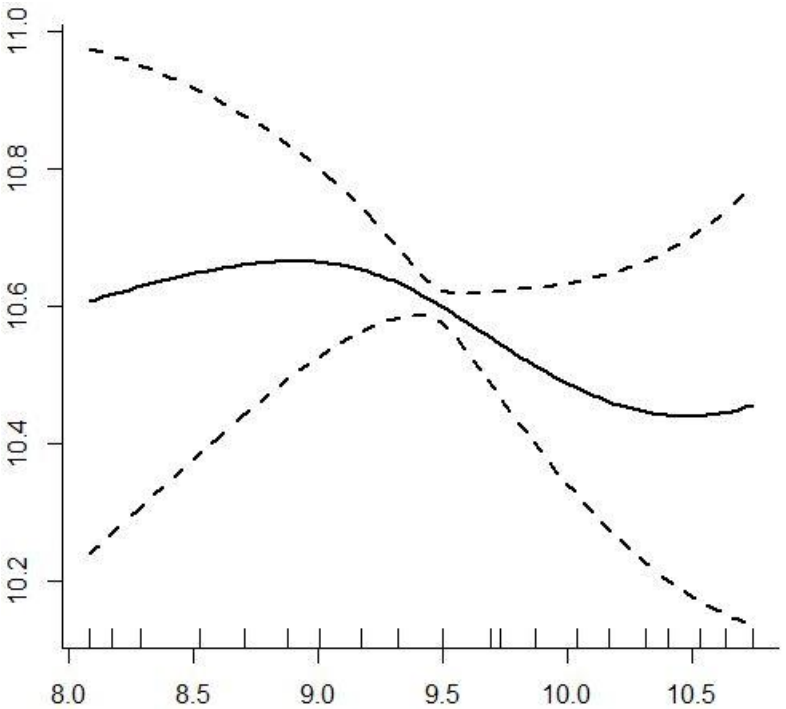

Figure 1 the impact of investment on regional economic growth

(1) Consumption and human resources to regional economic growth is significantly greater than investment and export. China used to rely on export and investment to stimulate regional economic growth, with the implementation of "innovation driven development" economic development strategy, the mode of economic growth has changed, the role of domestic demand in promoting economic growth has gradually strengthened, and the dependence of economic growth on foreign trade has gradually decreased.

(2) Investment has a non-linear influence on regional economic growth, which must be considered when we study regional economic growth. Ignoring the non-linear influence of investment on regional economic growth will underestimate the influence of consumption on economic growth, which has an important influence on the study of expanding domestic demand and realizing the double circular development mode of economy.

At the same time, considering the nonlinear characteristics of investment impact can significantly improve the accuracy of the model fitting. The results also show that it is necessary to consider this impact in the empirical analysis, only in this way we can more objectively and accurately grasp the characteristics of regional economic operation.

(3) Too high investment level can not promote economic growth. The empirical results show that when the investment level is higher than the threshold, investment no longer promotes regional economic growth.

According to the empirical results, we can draw the following suggestions

(1) It should continue to raise the level of domestic demand and appropriately control the level of investment. It should stimulate domestic demand 
through tax regulation and other methods, which can effectively promote regional economic growth; at the same time, it should moderately control or slow down investment, and formulate targeted investment strategies according to the existing investment level in different regions.

(2) It should strengthen the training of human resources and improve the skill level of labour force. Human resources have a significant positive impact on regional economic growth, it should also pay attention to the quantity of human resources and the quality of human resources. By increasing the vocational training market, expanding the scale of vocational schools and other strategies, the overall improvement of labour culture and skills level will effectively promote regional economic growth.

\section{REFERENCES}

[1] Onifade S T, Evik S, Erdoan S, et al. An empirical retrospect of the impacts of government expenditures on economic growth: new evidence from the Nigerian economy[J]. Journal of Economic Structures, 2020, vol9, pp.6-19. DOI:https://doi.org/10.1186/s40008-020-0186-7

[2] Hasan M A. Does globalization accelerate economic growth? South Asian experience using panel data[J]. Journal of Economic Structures, 2019, vol 8,pp.26-39. DOI:https://doi.org/10.1186/s40008019-0159-x

[3] Haini H. Examining the relationship between finance, institutions and economic growth: evidence from the ASEAN economies[J]. Economic Change and Restructuring, 2020, vol53,pp.519-542.

DOI:https://doi.org/10.1007/s10644-019-09257-5

[4] Kalaitzi A, Chamberlain T W. Exports and economic growth: some evidence from the GCC $[\mathrm{J}]$. LSE Research Online Documents on Economics, 2020,vol26,pp.203-205.

DOI:https://doi.org/10.1007/s11294-020-09786-0

[5] Gani A, Ahmad N . Has Economic Growth of China and India Impacted African Economic Prosperity?[J]. Atlantic Economic Journal, 2020, vol48,pp.375-385.

DOI:https://doi.org/10.1007/s11293-020-09674-2

[6] Qamruzzaman, M., Jianguo, W. Nexus between financial innovation and economic growth in South Asia: evidence from ARDL and nonlinear ARDL approaches[J]. Financial Innovation, 2018, vol4, pp.20-39. DOI:https://doi.org/10.1186/s40854-0180103-3
[7] Olayungbo D O, Quadri A. Remittances, financial development and economic growth in sub-Saharan African countries: evidence from a PMG-ARDL approach[J]. Financial Innovation, 2019, vol5, pp.9-34. DOI:https://doi.org/10.1186/s40854-019$0122-8$

[8] Nguyen H T, Luu H N, Do N H . The dynamic relationship between greenfield investments, crossborder M\&As, domestic investment and economic growth in Vietnam[J]. Economic Change and Restructuring, 2020, vol2,pp.1-25. DOI:https://doi.org/10.1007/s10644-020-09292-7

[9] Mohamed Abdouli, Sami Hammami. The Impact of FDI Inflows and Environmental Quality on Economic Growth: an Empirical Study for the MENA Countries[J]. Journal of the Knowledge Economy, 2017 , vol8,pp.254-278.DOI : https://doi.org/10.1007/s13132-015-0323-y

[10] Ge L, Ai S . Guangdong-Hong Kong-Macao Greater Bay Area public goods supply governance research based on data mining algorithms[J]. Journal of Ambient Intelligence and Humanized Computing, 2020,vol9, pp.75-84, DOI : https://doi.org/ 10.1007/s12652-020-02019-6

[11] Bsenberg S, Egger P, Zoller-Rydzek B. Capital taxation, investment, growth, and welfare[J]. International Tax and Public Finance, 2018, vol25, pp.1-52, DOI:https://doi.org/10.1007/ s10797-0179454-3

[12] Mushtaq, Saba. Causality between bank's major activities and economic growth: evidences from Pakistan[J]. Financial Innovation, 2016, vol2,pp.718,DOI:https://doi.org/10.1186/s40854-016-0024-y

[13] Chen S W, Xie Z, Liao Y. Energy consumption promotes economic growth or economic growth causes energy use in China? A panel data analysis[J]. Empirical Economics, 2018, vol55,pp.1019-1043,DOI:https://doi.org /10.1007/ s00181-017-1319-1.

[14] Zhang Bo,Fan Chao.Partially Linear Models with Kernelized Function and Their Application[J].Statistical Research, 2020, vol37, pp.110-128. DOI : https://doi.org/10.19343/j. cnki.11-1302/c.2020.01.009 